\title{
Naval and Oceanic Engineering: more than Ships and Offshore
}

\author{
Ingeniería Naval y Oceánica: más que Buques y Offshore
}

DOI: https://doi.org/10.25043/19098642.159

\author{
Marcos Salas ${ }^{1}$ \\ Cristian Cifuentes ${ }^{2}$ \\ Richard Luco ${ }^{3}$ \\ Astrid Santander ${ }^{4}$ \\ Gonzalo Tampier ${ }^{5}$ \\ Claudio Troncoso ${ }^{6}$ \\ Federico Zilic $^{7}$
}

\begin{abstract}
Traditionally, Naval and Oceanic Engineering has been focused on research in surface and submarine ships; and fixed and floating offshore structures. More than $90 \%$ of world trade is transported by sea, so it is not surprising that most research efforts have been focused on making merchant ships more efficient and safer. Something similar is happening in the offshore industry driven by the demand for energy. Despite the evident need to perform research in the traditional fields of Naval and Oceanic Engineering, new challenges have caused universities and research centers to tackle new fields of research. This paper presents some of the research and innovations developed at the Institute of Naval and Maritime Sciences (ICNM) of the Austral University of Chile (UACH). These new frontiers for research address problems as diverse as the capturing of energy from waves and currents [1], the development of structures and systems for aquaculture [2], the design of autonomous underwater vehicles [3], the use of solar energy for the propulsion of small boats [4] and the design of floating ports for remote areas [5].
\end{abstract}

Key words: Innovation, Naval Engineering, Ocean Engineering.

\section{Resumen}

Tradicionalmente la Ingeniería Naval y Oceánica ha estado enfocada a la investigación en naves de superficie y submarinas; y estructuras offshore fijas y flotantes. Más del 90\% del comercio mundial es transportado vía marítima por lo que no es de sorprender que la mayoría de los esfuerzos de investigación hayan sido enfocados a hacer los buques mercantes más eficientes y seguros. Algo similar ocurre en la industria offshore impulsada por la demanda de energía. No obstante la evidente necesidad de investigar en los campos tradicionales de la Ingeniería Naval y Oceánica, nuevos desafíos han hecho que las universidades y centros de investigación aborden nuevos campos de investigación. Este trabajo presenta algunas de las investigaciones e innovaciones desarrolladas en el Instituto de Ciencias Navales y Marítimas (ICNM) de la Universidad Austral de Chile (UACH). Estas nuevas fronteras para la investigación abordan problemas tan diversos como la captación de energía de olas y corrientes [1], el desarrollo de estructuras y sistemas para la acuicultura [2], el diseño de vehículos autónomos submarinos [3], el aprovechamiento de la energía solar para propulsión de pequeńas embarcaciones [4] y el diseńo de puertos flotantes para zonas remotas [5].

Palabras claves: Innovación, Ingeniería Naval, Ingeniería Oceánica.

Date Received: June $2^{\text {nd }} 2017$ - Fecha de recepción: Junio 2 de 2017

Date Accepted: November 23 2017 - Fecha de aceptación: Noviembre 23 de 2017

\footnotetext{
${ }^{1}$ Instituto de Ciencias Navales y Marítimas. Universidad Austral de Chile. Email: msalas@uach.cl

${ }^{2}$ Instituto de Ciencias Navales y Marítimas. Universidad Austral de Chile. Email: cristiancifuentes@uach.cl

${ }^{3}$ Instituto de Ciencias Navales y Marítimas. Universidad Austral de Chile. Email: rluco@uach.cl

${ }^{4}$ Instituto de Ciencias Navales y Marítimas. Universidad Austral de Chile. Email: astridsantander@uach.cl

${ }^{5}$ Instituto de Ciencias Navales y Marítimas. Universidad Austral de Chile. Email: gonzalo.tampier@uach.cl

${ }^{6}$ Instituto de Ciencias Navales y Marítimas. Universidad Austral de Chile. Email: claudio.troncoso@uach.cl

${ }^{7}$ Instituto de Ciencias Navales y Marítimas. Universidad Austral de Chile. Email: efe011@gmail.com
} 


\section{Introduction}

The Institute of Naval and Maritime Sciences has a long history of research and innovation. It has several laboratories, including its own hydrodynamic test channel. Many of its research efforts make use of experimental methodologies using scale models. Traditionally, test channels have been used to determine vessel resistance and wave behavior, however, with the right instruments it can be used in objectives as diverse as measuring the efficiency of wave energy converters [6] or tidal turbine forces. The experimental tests are also compared with computer simulations made with CFD tools.

\section{Marine Energies}

The ICNM is part of the recently created Center for Research and Innovation of Marine Energy (MERIC), a consortium composed of Universities and Research Centers funded by the Government of Chile with the express objective of promoting research in the field of non-conventional renewable energies (NCRE). The work of the ICNM in this field specifically consists of investigating the devices that capture wave energy [6], the so-called WEC (Wave Energy Converter) mechanisms and the capture of tidal energy [7].

Chile's energy demand has been growing in the last decades and it is expected to continue increasing with the development of the country. Conventional sources of renewable energy, such as traditional hydroelectric power plants, are almost fully exploited or exposed to strong opposition from environmental groups. In the current situation, more than half of the electricity required by Chile is produced by thermal power plants that burn oil, coal or gas. The Chilean government is fully aware of this vulnerability and is making efforts to increase the contribution of other sources of renewable energy; it is intended that by 2025 , $20 \%$ of the energy consumed in the country will come from NCRE.

The wave energy potential in Chile is among the largest in the world, with an energy potential that has been estimated between 164 and 240 GW [8].
Although significant advances have been made in the development of wave energy converters (WEC) over recent years, they are still considered to be at an early stage of development, compared to other NCRE technologies, such as wind, hydroelectric or solar energy.

The region of the Chilean fjords, between the $41^{\circ}$ $30^{\circ}$ and $55^{\circ}$ parallels, is perhaps the most suitable for tidal projects, not only because the currents are strong and predictable, but also because there is almost no efficient alternative. In this region there are many small towns and hundreds of fish farming centers, isolated and without access to the electricity grid. Here electricity is produced mainly by generators, sometimes during limited hours of the day.

This section shows the evaluation of a WEC, with a scale model, in which its response was measured under different wave conditions in the test channel, as shown in Fig. 1. The experimental configuration for the converter WEC consisted of two ultrasonic measuring instruments for incident waves and WEC movement, an adjustable damper connected to a load cell to measure force and data acquisition software (LabView). The experimental results were compared with the numerical results obtained by WAMIT in the form of transfer function and output power. The comparative are in accordance with the variation of the set of wave frequency parameters, wave height and damping factors as shown in Fig. 2. These developments are the first steps towards the specialization of this tank in

Fig. 1. WEC in Canal tests

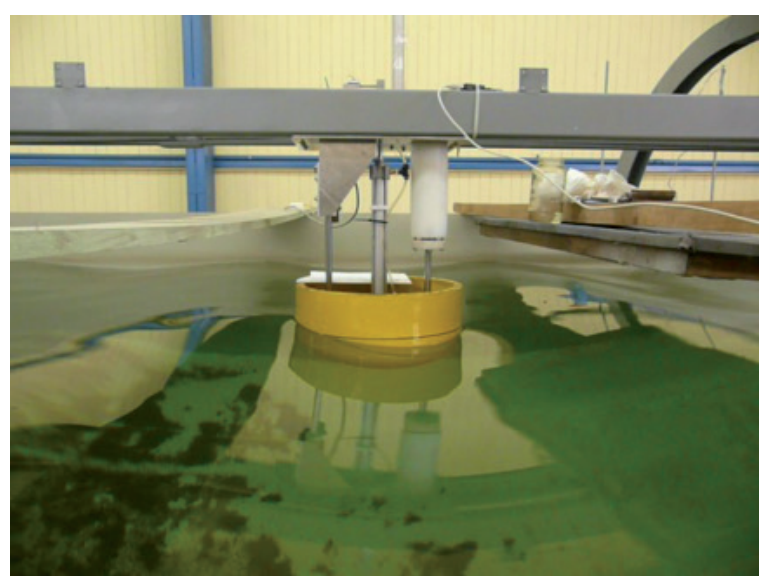


Fig. 2. FEM turbine analysis

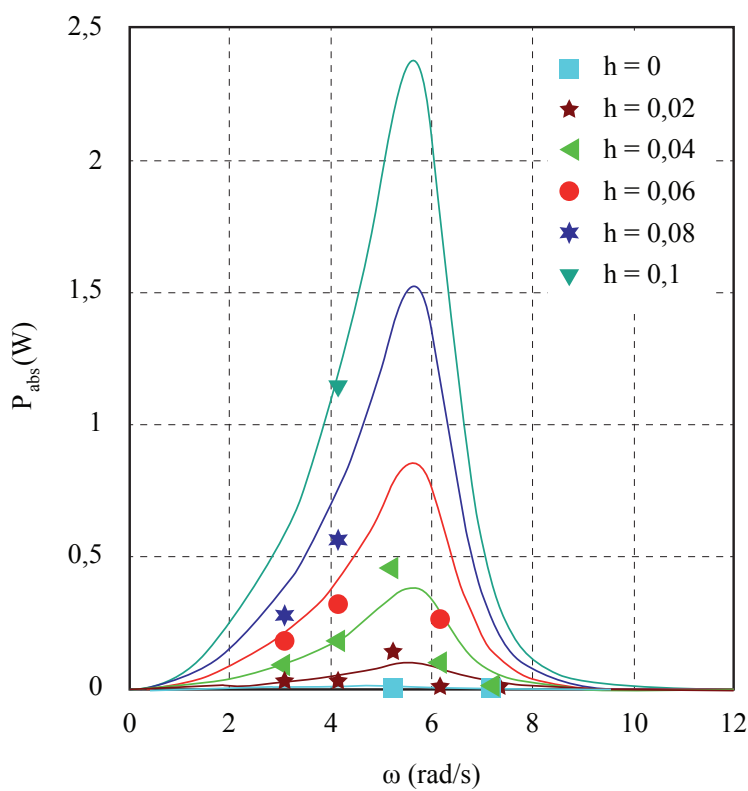

Experimental hydrodynamics of marine renewable energy technologies.

In another aspect of marine energy research, the development of a hydrokinetic rotor is included in the evaluation of a horizontal axis rotor using NACA profiles, as well as NREL profiles (National Renewable Energy Laboratory). Different configurations of the profile along the propeller blades were used for the design of these rotors. Configurations were evaluated in terms of efficiency, structural integrity, and cavitation. The investigation consisted of a fluid-dynamic evaluation of the hydrokinetic rotor blades, considering the rotor running inside a diffuser. The performance evaluation was carried out using the blade element method and in the structural evaluation, using the finite element method. For the selection of the design, an optimization process was defined to determine the configuration of profiles that best meet the established design requirements. The results of this work show the need for design profiles that consider the exclusive requirements of its use in a hydrokinetic rotor.

For the realization of the fluid-dynamic analysis of the rotor, the Qblade program was used, a program that integrates XFOIL in a rotor design and analysis environment using the blade element momentum method (BEM), allowing the design and dynamic calculation of the rotor blades. XFOIL is a free computer program that allows the distribution of pressures on the faces of the profile to be calculated together with its performance coefficients. The results obtained allow NREL profiles to be established with the characteristics that allow more efficient rotors to be designed in comparison with the NACA profiles. Figs. 3 and 4 show the results for both rotors.

Fig. 3. Power Coefficient

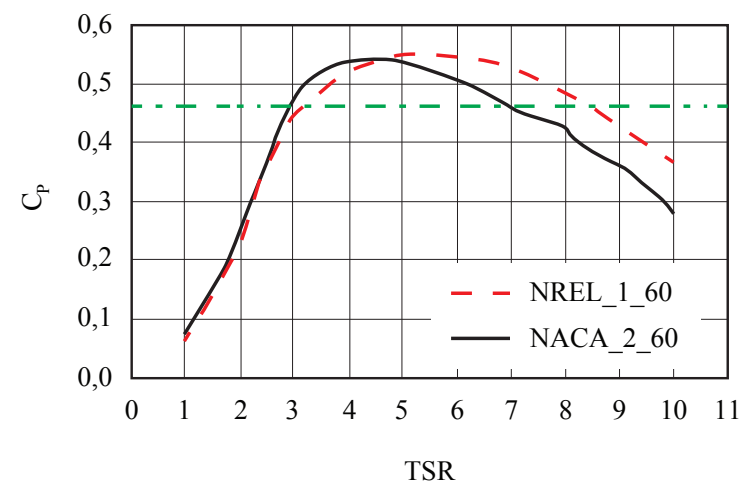

Fig. 4. Thrust Coefficient

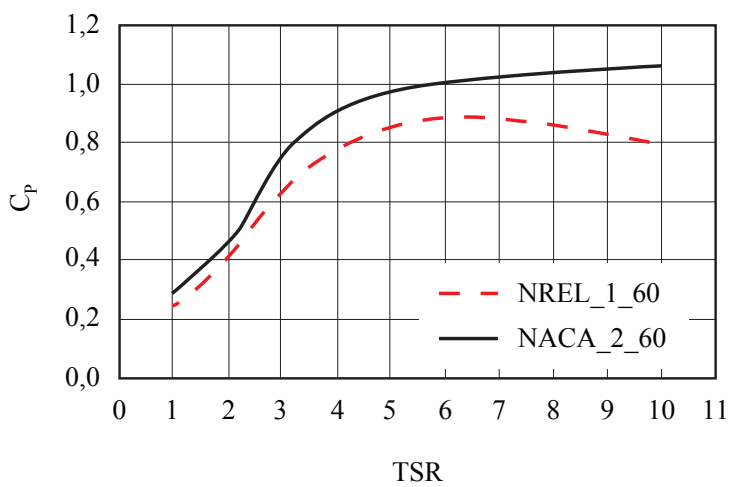

\section{Engineering Applications in Aquaculture}

The development of large-scale aquaculture in countries such as Norway and Chile has led naval architects and ocean engineers to develop studies, both numerical and experimental, to determine the forces and corresponding deformation of flexible structures such as the nets used in floating cages. The culture centers, mainly for salmon, operate with 
square or circular shape cages (Fig. 5), installed in protected areas such as bays and inside channels and fjords, to avoid the effect of waves and currents present in the open sea. The feeding of the fish is done by automated systems installed on a pontoon as shown in Fig. 6. The basic components of the cages are: a float that acts as a flotation reserve to support the weight of the net and shapes the same, the net, which encloses the production volume where the fish and the ballast system are found, which extend the net and help to control the deformation of the same when faced with current loads.

Fig. 5. Farming center in southern Chile (www.sermar.cl)

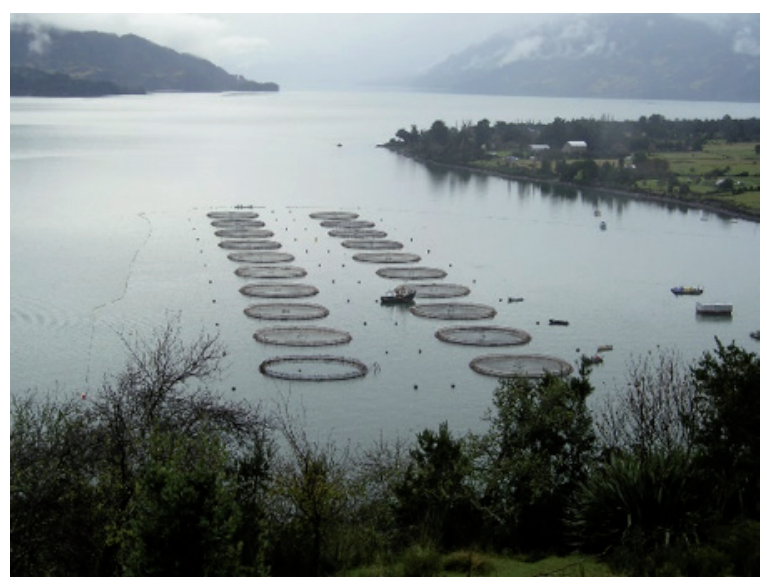

Fig. 6. Feeder and control pontoon

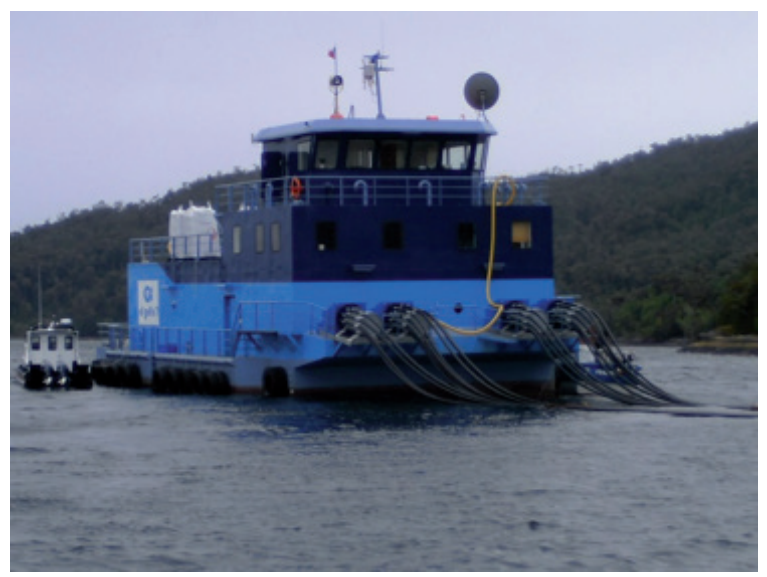

The study of the hydrodynamic behavior of raft cages is complex due to the dependence between the drag force on the nets and the deformation of the same. In the same way, for circular cages constructed out of HDPE (High Density
Polyethylene), the rings that form the surface float deform when facing wave loads, directly influencing the tensions in the mooring lines.

Additionally, the reduction of current speed when crossing networks, a phenomenon known as the shadow effect, adds complexity to numerical and experimental modeling. This effect has a direct impact on the volume available inside the cages [9]. Several studies, including those covering the behavior of the fish inside the cages, biofouling on the nets and flow into the culture centers have been developed by various specialists to improve production in increasing the safety of these structures.

There are several numerical methods for estimating the hydrodynamic response of cages. The nets have been modeled using consistent bar elements in a finite element model, panel elements and finite element models using bars and buoys that allow the submerged weight of the network to be adjusted to create a reduced model of elements that simulates the mechanical properties and inertial network in the physical model [9]. An example of results obtained by the bar and buoy method can be seen in Fig. 7, which also includes the study of the density of elements in direct comparison with the deformation resulting from experimental tests.

Regarding the response of the cages to waves, it has been determined that the forces on the mooring lines are directly related to the wave height [10]. In the face of combined wave and current effects, depending on the combination of height and wave period and current speed, the effect of wave loading can be of the same importance range as current charging, which implies a careful modeling of both effects.

In exposed areas, fish farms must operate autonomously with minimal human intervention and the cage anchoring system will be shared with the platform that houses equipment and food for the fish. Results obtained for systems exposed to extreme wave and current conditions, both in numerical models and field tests, demonstrate the feasibility of the installation and operation of these structures and open the door for the future development of the industry in exposed areas [11]. 
Fig. 7. Comparison of deformations in networks subject to current [9]

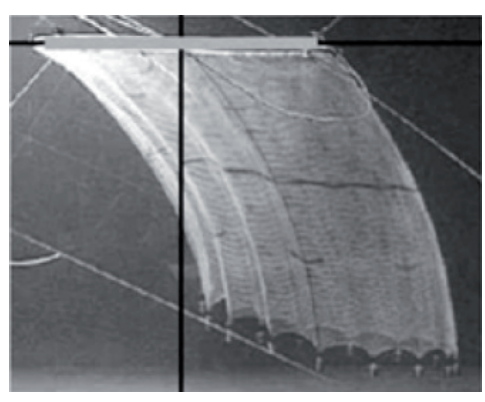

a) Experimental model

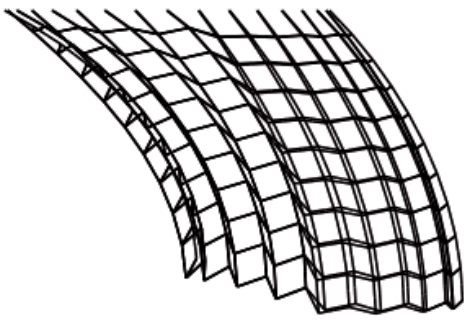

b) Numeric thick mesh

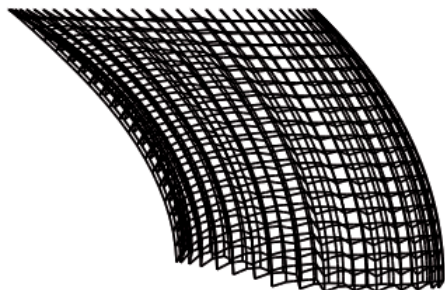

c) Numeric fine mesh
In the open sea conditions are optimal for fish due to the constant exchange of nutrients in the water column. The almost unlimited availability of space would allow the production of a greater volume of fish, in addition to opening up of areas to new species with greater commercial value.

The development of aquaculture depends on an increase in both numerical and experimental research and field research, where naval and oceanic engineers can contribute their knowledge. The use of the knowledge gained in the design, construction and operation of ships and floating structures can and should be transferred to fish farms to ensure sustainable and sustainable development in offshore aquaculture.

\section{Autonomous Submarine Vehicles}

Unmanned underwater vehicles are divided into ROVs (Remote Operated Vehicles or remotely operated vehicles), devices connected via a cable to a station or surface vessel; AUVs (Autonomous Underwater Vehicles or autonomous underwater vehicles) that operate autonomously and without physical connection to the surface, which use some form of artificial intelligence; and a third group of hybrid vehicles that is a combination of the previous two.

One of the lines of research in force at the ICNM is the development of an autonomous submarine vehicle or AUV. Design criteria were established based on a proposed oceanographic study for a coastal area of Chile (39० 48'30 "S 73¹4'30"W), which covers the entire continental shelf of said geographical area $\left(4100 \mathrm{Km}^{2}\right)$. The maximum distance from the coast is $26 \mathrm{NM}$, while the minimum distance is $16 \mathrm{NM}$, with depths reaching up to $200 \mathrm{~m}$. The device must be able to navigate without human intervention from the coast to the limit of the platform, to later return.

The basic design has a length of $2 \mathrm{~m}$ with a circular master section of $160 \mathrm{~mm}$ in diameter, with a cylindrical central watertight compartment of $1 \mathrm{~m}$ in length, watertight lids at its ends and two flooded compartments of $0.5 \mathrm{~m}$ at both ends. To date, a prototype tele operated in the Hydrodynamic Test Channel of the Universidad Austral has been tested with successful results in mechanical and hydrodynamic systems tests. A second prototype is currently under construction in accordance with the preliminarily design requirements established and that will be able to perform missions in open and protected waters.

Given the characteristics of the environment, it is extremely difficult to establish communication with a ground station since salt water cancels the electromagnetic signals, while acoustic systems are expensive and limited in their range of operation. Moreover, the signals of the global positioning systems can only be obtained on the surface, so when submerging the AUV must use the other onboard measuring devices to navigate by estimating control signals.

The AUV in development will have an artificial intelligence system to navigate without human intervention and only using an initial programming defined by the user. The basis of this system is 
Fig. 8. AUV in Channel tests

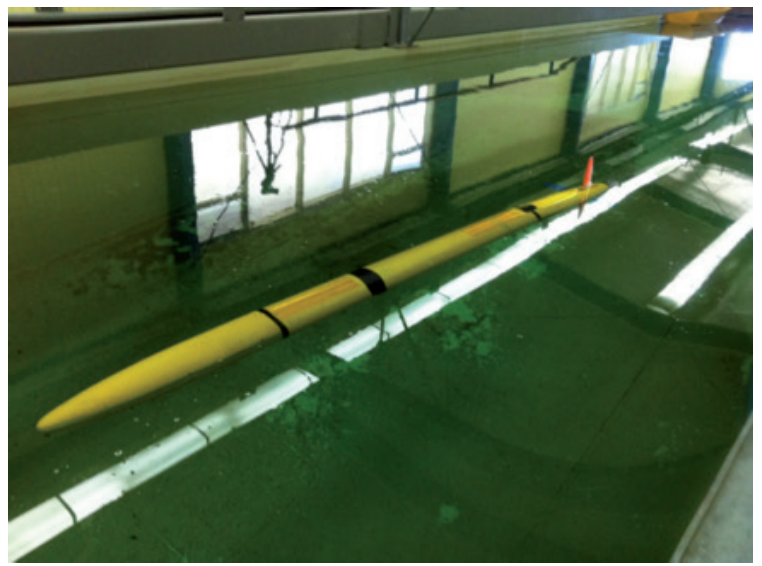

software capable of processing the information coming from sensors (accelerometer, gyroscope, magnetometer, sonar, GPS, etc.) and can, therefore, generate useful control signals to achieve the fulfillment of the mission.

The device has a multipurpose area in the bow for the assembly of measurement equipment, either cameras to capture images or sensors for measuring environmental parameters. This area has been specifically designed so that the device can serve any type of user.

The potential of the platform includes substantially improving the environmental monitoring capabilities sustained over time and greater efficiency, which will benefit aquaculture companies, government entities and port agencies, in addition to others.

Solar energy for small electric propulsion boats

The main disadvantage of electric propulsion systems in smaller ships lies in the limited capacity to store energy on board, due to the large weight and volume of batteries required. For this reason the power of the engine is generally modest and consequently the speed of the boat it is relatively low compared to what could be achieved by a conventional propulsion system based on an internal combustion engine. This is the reason why electric propulsion in smaller vessels is almost exclusively limited to displacement hulls in the low
Fig. 9. AUV configuration

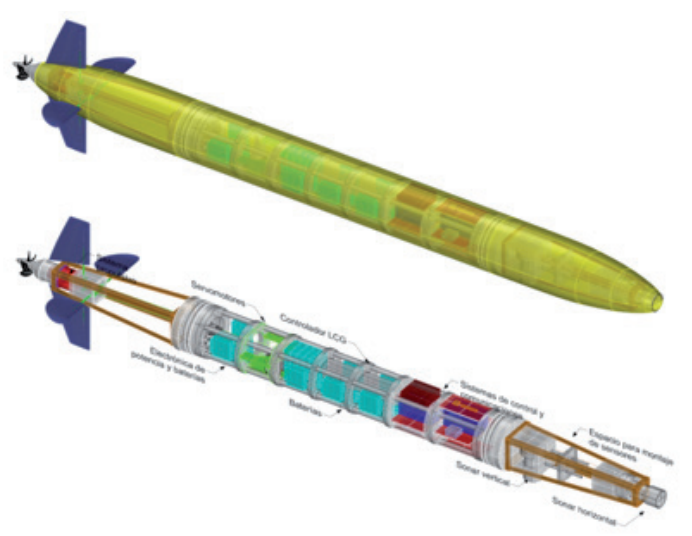

speed range, where the resistance to advancement is minimal.

The advantages of electric propulsion are; a very quiet operation, without the emission of pollutants to the environment and virtually no maintenance of the engines, compared to internal combustion engines, which must be subject to periodic preventive maintenance, in addition to being permanently subject to potential damage of parts due to failure of lubrication, cooling and corrosion, which directly affects the operating costs of the engine. On the other hand, the limited autonomy that depends on the storage capacity of the batteries, can be increased by having on-board photovoltaic panels, normally on flat surfaces in roofs or ceilings. This allows the batteries to be recharged continuously, provided natural light is available.

Having recognized the advantages and disadvantages of electric propulsion, this section shows a vessel in operation for the transport of passengers in the city of Valdivia. Table 1 shows the main characteristics of the boat that was built by Alwoplast shipyards (www.alwoplast.cl). The boat has been designed with the minimum possible displacement and for this purpose the hull is constructed from composite materials. Its main use is the daytime transportation of passengers in the rivers of the city of Valdivia. Trips are limited to a few hours and the battery bank has been sized to provide the necessary energy for each trip, at the end of which the boat returns to its base port in the city. 
Table 1. Main characteristics of the solar boat

\begin{tabular}{lr}
\hline Total length & $9.5 \mathrm{~m}$ \\
\hline Sleeve & $3.0 \mathrm{~m}$ \\
\hline Strut & $1.4 \mathrm{~m}$ \\
\hline Openwork & $0.35 \mathrm{~m}$ \\
\hline Displacement & $4.8 \mathrm{t}$ \\
\hline Passengers (crew) & 12 \\
\hline Crew & 1 \\
\hline Maximum speed & 6 knots \\
\hline Speed system & $4 \mathrm{KW}$ \\
\hline Engine power & $48 \mathrm{~V}$ \\
\hline DC & $1.6 \mathrm{KW}$ \\
\hline Solar panels & compound \\
\hline Hull material
\end{tabular}

Fig. 10. Boat with electric propulsion operating in Valdivia, Chile. [4]

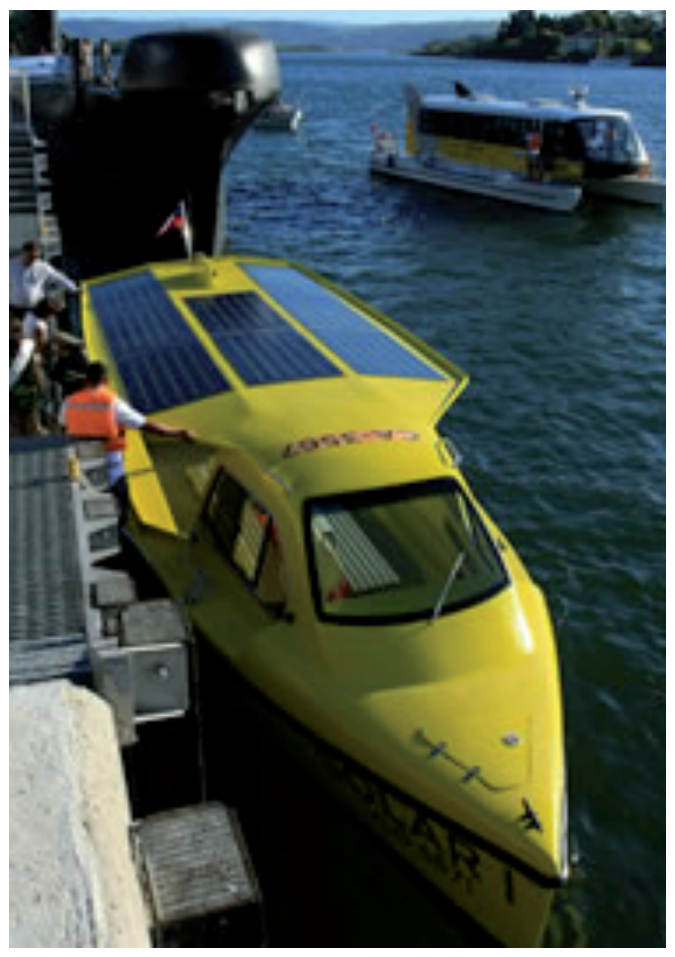

A roof covered with photovoltaic panels has been designed, see Fig. 10, normally placing a heavy weight on deck that could be a problem for the stability of the boat. However, this moderate weight is amply compensated by the greater weight of the battery bank, conveniently located as low as possible. The panels continually recharge the batteries during the trip in daytime conditions. Notwithstanding the above, recharging batteries during the trip is not necessary, if at the beginning of the trip the batteries are at full capacity.

There is also the possibility of recharging the bank during the night connecting a charger to the local electrical network. This is not necessary if the boat stays the next day in port, with the load being achieved through solar panels, without incurring electricity costs. The electric propulsion is extremely silent, which is especially advantageous in a passenger vessel.

Currently there are 3 vessels with solar propulsion operating in Valdivia. The results, after several years of operation have been satisfactory, which means that the costs of maintenance and operation of the propulsion system are practically null. Passengers are extremely satisfied with the silent and non-polluting navigation.

\section{Design of floating ports for remote areas}

The south of Chile is an area of extreme difficulty of access, the existence of thousands of islands and canals makes the construction of roads extremely difficult and in many cases maritime transport is the main supply route, and ports and appropriate conditions must be provided to ensure the connectivity of those regions. The Government of Chile has developed a connectivity program for remote regions that, among other solutions, has favored the construction of floating ports.

According to Tsinker [5], it is advisable to install a floating dock where:

- It has protected waters, where the waves generated by the wind or the movement of boats do not exceed 1 to $1.5 \mathrm{~m}$ in height,

- Where the soil quality does not allow foundations for fixed structures.

- The change in sea levels is high due to the large difference in tides.

- In seismic zones, since floating docks are less affected by earth movements during an earthquake. 


\section{Main components of a floating port}

The main components of a floating port are the following:

- Floating pontoon

- Access bridge

- Anchoring and mooring system

The floating pontoon is a naval artifact, which is designed to meet certain functionality requirements (load capacity, vehicle / people traffic, deck area, behavior at sea, others). Depending on the design requirements of the dock, it can be designed using several configurations, including one or more modules joined by a continuous cover or a pivoting mechanism. Although it is a simple hydrostatic problem, careful attention must be paid to the rolling load displacement on the deck, to avoid displacements or rotations of the pontoons that may impede proper operation, see Figs. 11 and 12.

The access bridge is the connection between the pontoon and the coast, which must be designed to provide an effective solution for the traffic of vehicles, cargo and people. Considering that there are variations in the water level (changes of tide in the sea, changes of seasonal levels in lakes and rivers) in the site of the bridge, the use of articulations should be considered in its design, allowing the bridge to vary the position from the end on which it is resting on the pontoon. In addition to its design, special care must be taken in verifying the angle of inclination reached by the bridge in the different water level conditions.

The pontoon mooring system must allow the safe and efficient operation of the floating dock, keeping the dock in a stable relative position with respect to the access bridge. Mooring systems can be composed of elements that are deployed on the coast or offshore, which can be of anchor line type, anchor pillars or articulated beams.

In addition to the static analysis of the load on the pontoons, the dynamic effects must also be considered, environmental loads such as waves or the effect of wind must be considered. The dynamic analysis of the movement of ships is well documented, however, for floating structures the problem has additional variables. Due to the

Fig. 11. Effect of moving a load on pontoons with different buoyancy reserves
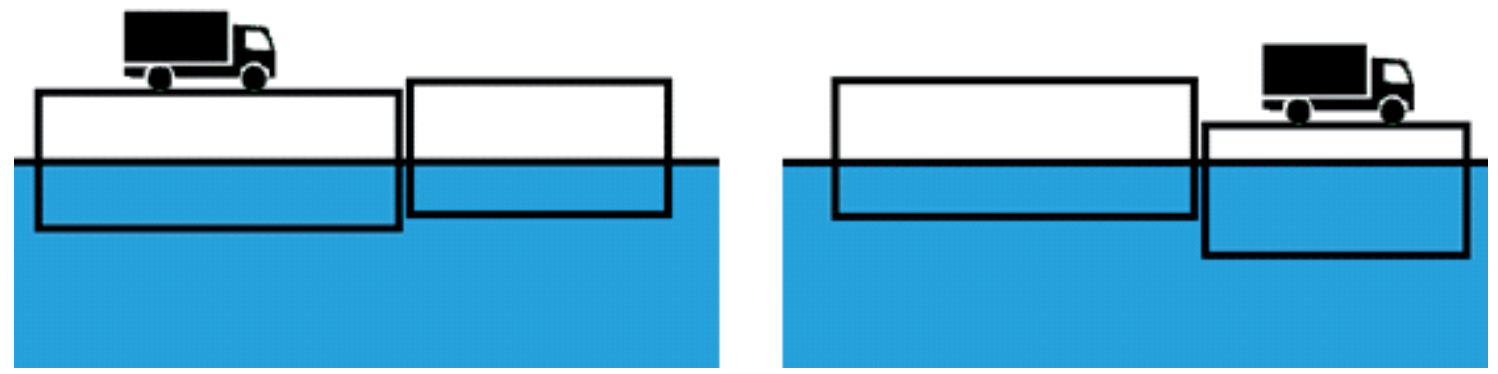

Fig. 12. Effect of positioning a load on a pontoon fixed to another by means of an articulated joint
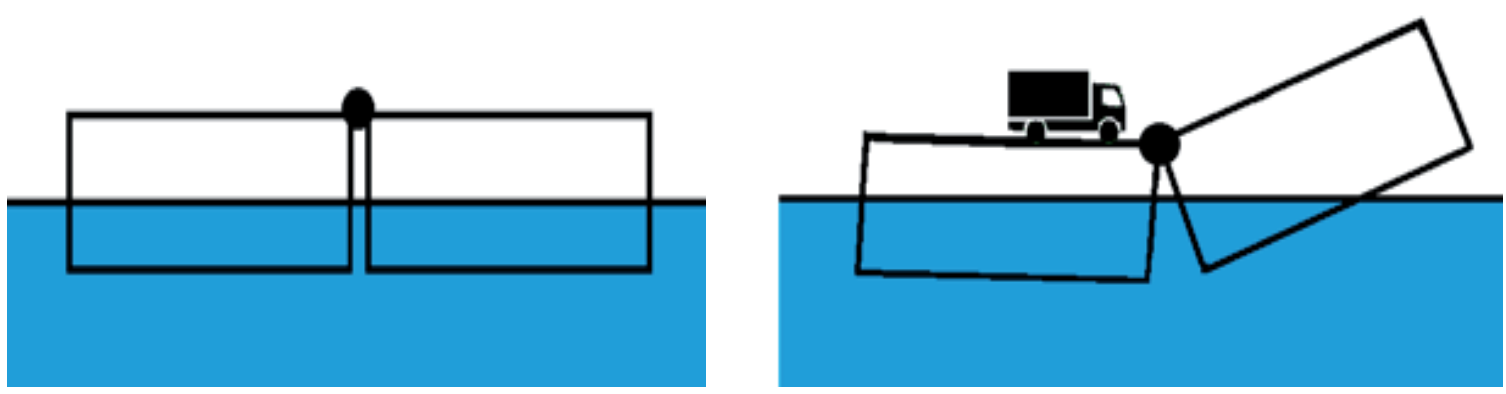
complex interaction between the floating structures, the anchoring and the fluid medium, it is advisable, in addition to the analytical studies and numerical simulations, to carry out experimental tests with scale models, considering the characteristic waves and the bathymetry of the place where a floating port is proposed. It is important to determine the significant wave height and period that determines the closure of the port due to unsafe operating conditions, taking as a criterion the limits that ensure comfortable work on the floating port. for which the limits defined in Table 2 can be taken as an example. In addition to establishing criteria for the closure of port operations, the floating structure must be designed to survive extreme conditions that ensure its useful life, for example, 100 years. Fig. 13 shows wave tests for a floating port in southern Chile, under typical conditions imposed by the zone fetch, 13a, and Fig. 13b shows waves with a return period of 100 years.

\section{Conclusions}

It is clear that professional training must be flexible enough to adapt to the new challenges that Naval and Oceanic Engineers needs to address. The experience of the labor market in Chile indicates that the training is comprehensive and appropriate for the requirements of the industry. In Chile there are many Naval Engineers developing vessels and systems for aquaculture, including high speed vessels for transporting personnel, control and habitability pontoons, automatic pneumatic feeding systems capable of feeding hundreds of thousands of fish, wellboats capable of transporting live salmon under controlled $\mathrm{PH}$ conditions with optimum temperature and oxygenation. Innovation in aquaculture is through the application of various buoyant materials, new environmentally friendly antifouling systems, safer anchoring systems and the projection of the industry indicates that the

Table 2. Criteria for accelerations and roll angle (NORDSFORK, 1987)

\begin{tabular}{|c|c|c|c|c|}
\hline \multirow{2}{*}{ Level } & \multicolumn{4}{|c|}{ Comfort criteria (rms) } \\
\hline & Description & $\begin{array}{c}\text { Vertical } \\
\text { Acceleration }\end{array}$ & $\begin{array}{c}\text { Transverse } \\
\text { Acceleration }\end{array}$ & Roll \\
\hline I & Light manual work & $<0.20 \mathrm{~g}$ & $<0.10 \mathrm{~g}$ & $<6.0^{\circ}$ \\
\hline II & Heavy manual work & $<0.15 \mathrm{~g}$ & $<0.05 \mathrm{~g}$ & $<4.0^{\circ}$ \\
\hline III & Intellectual work & $<0.10 \mathrm{~g}$ & $<0.05 \mathrm{~g}$ & $<3.0^{\circ}$ \\
\hline IV & Transit of passengers & $<0.05 \mathrm{~g}$ & $<0.04 \mathrm{~g}$ & $<2.5^{\circ}$ \\
\hline $\mathrm{V}$ & Passengers on cruise ships & $<0.02 \mathrm{~g}$ & $<0.03 \mathrm{~g}$ & $<2.0^{\circ}$ \\
\hline
\end{tabular}

Fig. 13a. Wave tests typical condition given by fetch. $\mathrm{H} 1 / 3=0.52 \mathrm{~m} \mathrm{~T}=2.99$

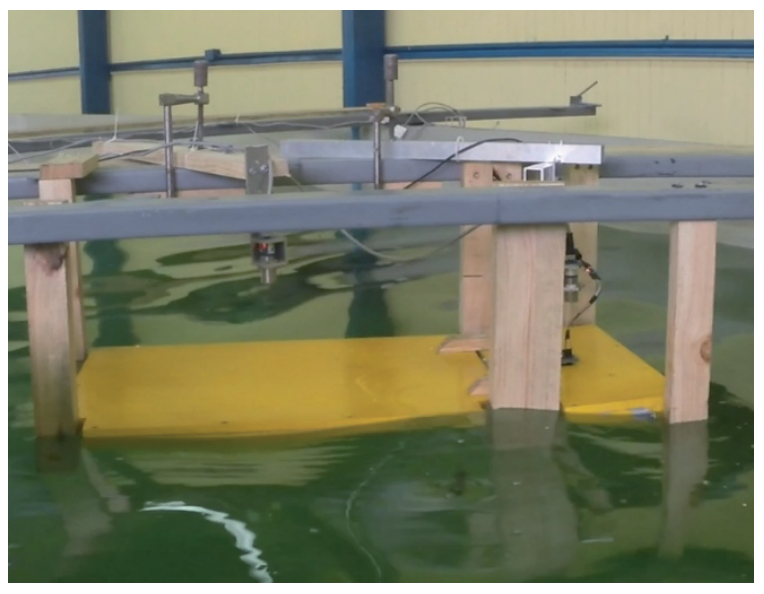

Fig. 13b. Wave tests return period 100 years. $\mathrm{H} 1 / 3=1.38 \mathrm{~m} \mathrm{~T}=4.15 \mathrm{~s}$

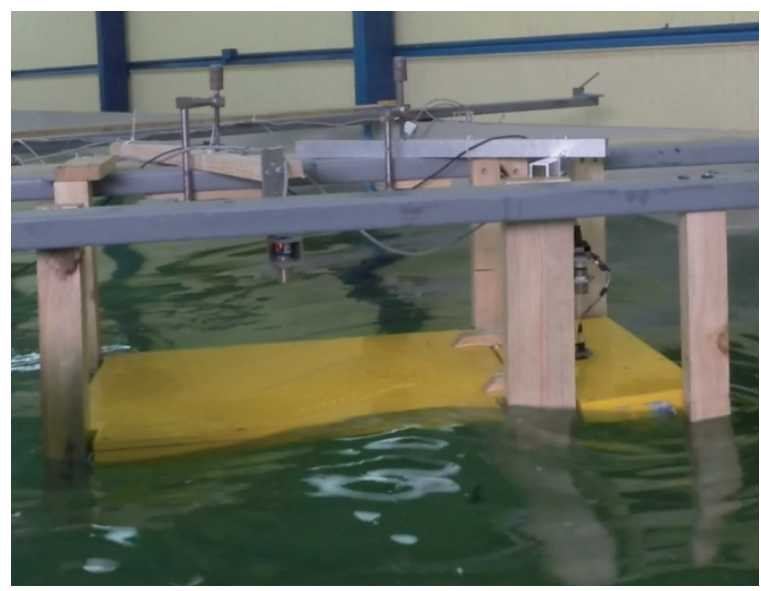


future trend is to develop offshore systems that will be able to withstand exposed sea conditions. More recently, the need to take advantage of new sources of renewable energy makes it possible for Naval Engineers to design systems to obtain energy from the waves and currents generated by the tides in Chilean channels. It is difficult to predict what new challenges will exist for the future generations of Naval and Oceanic Engineers, perhaps the only sure thing to affirm is that Naval and Oceanic Engineering is a profession that must always provide innovative solutions for the benefit of society and the environment.

\section{References}

[1] TAMPIER, G.; SALAS, M.; TRONCOSO, C. AND GRÜTER, L. "Wave Energy Converter and Hydrokinetic Rotor Developments in Chile". 10th Annual Energy Harvesting Workshop. Blacksburg, USA, September 13 - 16, 2015.

[2] SALAS, M. AND DI GIROLAMO G. "Engineering Applications in Chilean Aquaculture". Journal of Ocean Technology. Vol. 5 No2, 2010.

[3] ZILIC, F.; G. TAMPIER; R. LUCO. "Desarrollo de Vehículo Submarino Autónomo para Exploración Oceanográfica". XXIV Congreso Panamericano de Ingeniería Naval. 18 al 22 de Octubre 2015 , Montevideo, Uruguay.

[4] SALAS, M.; LUCO, R. AND EKDAHL, H. "Energía Solarpara Propulsión de Embarcaciones Fluviales" First International Conference
IDS2013 - Amazonia, 17th-19th July 2013, Iquitos, Peru.

[5] Tsinker, G.P. Floating Ports 1986

[6] TAMPIER, G. AND GRÜTER, L. "Development of an experimental test bed for Wave Energy Converters". WTE'14 -First Workshop on Wave and Tidal Energy, Valdivia, Chile. 29th to 31st October 2014.

[7] TRONCOSO, C. AND TAMPIER, G. "Design of Hydrokinetic Rotor using NACA and NREL Profiles". WTE'14 -First Workshop on Wave and Tidal Energy, Valdivia, Chile. 29th to 31st October 2014.

[8] MONÁRDEZ, P. et al.; "Evaluation of the potential of wave energy in Chile", OMAE2008 - International Conference on Offshore Mechanics and Arctic Engineering, 2008.

[9] C. CIFUENTES AND M. H. KIM, "Numerical simulation of wake effect in nets under steady current", in Proceedings of the ASME 2015 34th International Conference on Ocean, Offshore and Arctic Engineering OMAE2015, 2015, pp. 1-10.

[10] C. CIFUENTES, "Dynamic analysis of cage systems under waves and current for offshore applications", Texas A\&M University, 2016.

[11] C. CIFUENTES AND M. H. KIM, "Dynamic analysis for the global performance of an SPM-feeder-cage system under waves and currents", China Ocean Eng., vol. 29, no. 3, pp. 415-430, 2015. 